\title{
Darcy Ribeiro e UnB: intelectuais, projeto e missão
}

Adelia Miglievich-Ribeiro ${ }^{a}$

\section{Resumo}

A história da Universidade de Brasília (UnB), desde sua concepção original, lutas por sua implantação e o golpe sofrido em 1964, tendo seu campus invadido por tropas militares, é recordada para somar ao debate sobre os intelectuais públicos brasileiros que, nos anos 1950 e 1960, abraçavam um certo projeto de nação que via na educação e na ciência suas forças constitutivas. Faço uso da categoria Intelligentsia de Mannheim, que fortalecia o argumento do intelectual engajado no planejamento social com vistas às necessárias mudanças. Darcy Ribeiro é um deles. Mediante ainda as noções de "projeto" e "missão", tento explicar aquela que também poderia ser chamada "geração da utopia", sendo a UnB um dos projetos em curso que nascia dentro de um "campo de possibilidades" abruptamente modificado. Revisitar a missão contida na UnB, atualizando-o em razão de inéditos "campos de possibilidade", talvez seja uma tarefa necessária ao debate educacional hoje.

Palavras-chave: Darcy Ribeiro. Intelectuais. Universidade. UnB. Campo de possibilidades.

\section{Apresentação}

A UnB é uma utopia vetada, é uma ambição proibida, por agora, de exercer-se. Mas permanece sendo, esperando, como a nossa utopia concreta, pronta a retormar-se para se repensar e refazer, assim que recuperarmos a liberdade de definir

o nosso projeto como povo e a universidade que deve servi-lo (Darcy Ribeiro, UnB: invenção e descaminho, 1978, p. 41).

Na década de 1950, a ideia mannheimiana de intelligentsia era vigorosa na forma como foi recepcionada no Brasil, caracterizando os chamados intelectuais

\footnotetext{
a Universidade Federal do Espírito Santo - UFES. Vitória, Espírito Santo, Brasil. 
públicos, engajados nos projetos de modernização do país ${ }^{1}$. Tratava-se de uma intelectualidade que se colocava francamente como porta-voz dos interesses nacionais. Para este grupo, sua autocompreensão e a compreensão de sua sociedade estavam intimamente ligadas de maneira que seus intelectuais se apresentavam como sujeitos sociais detentores de um propósito intervencionista na sociedade.

Para tanto, a aproximação com o Estado, dado seu caráter centralizador no Brasil, era inevitável, o que não significa despojar o intelectual público de um sentido de autonomia na escolha por um ou outro caminho em face das questões efervescentes na sociedade brasileira. Subjaz aqui a crítica a uma sociologia dos intelectuais de matriz institucionalista que insistiria em dividir a participação intelectual entre "acadêmicos" e "extra-acadêmicos" ou entre "ciência" e "pré-ciência", negligenciando que, dentro ou fora da universidade, a geração intelectual de 1950 produziu conhecimentos que reafirmaram sua missão política e social na construção de um projeto de nação, a exemplo da intensa participação da maioria na condução das políticas educacional e cultural. A educação, digase de passagem, era central no debate e se apostava nas ações planejadas para sua universalização ${ }^{2}$. O encontro entre Anísio Teixeira (1900-1971) e Darcy Ribeiro (1922-1997) no Centro Brasileiro de Pesquisas Educacionais (CBPE) ${ }^{3}$ é emblemático deste tempo dos "intelectuais missionários". Juntos, os dois homens públicos enfrentaram não poucos embates perseguindo o projeto da educação pública, laica, gratuita, de qualidade.

Contar um pouco da missão traduzida na construção da Universidade de Brasília (UnB) é refletir sobre um projeto que, ainda que interrompido, simbolizou um ato de vontade e um compromisso que não devem ser esquecidos, em que pesem as alterações inevitáveis no "campo de possibilidades", isto é, a singularidade de seu contexto que impunha também os limites e as potencialidades para a execução dos projetos (VELHO, 1981; VILHENA, 1997). O projeto da UnB representou uma crítica severa ao sentido da ciência, das tecnologias e da

\footnotetext{
Um estudo sobre Karl Mannheim em suas influências, de modo especial, no meio intelectual brasileiro, pode ser lido em Villas Bôas (2002).

2 Sobre as matrizes institucionalista, sociológica e ideológica na interpretação da imaginação intelectual brasileira no século XX e algumas análises críticas, vale conferir Wanderley Guilherme dos Santos (1978), Peirano (1992); Miglievich-Ribeiro (2015), dentre outros.

3 O Centro Brasileiro de Pesquisas Educacionais (CBPE), criado em 1955 no governo de Juscelino Kubitschek, ligava-se ao Inep (Instituto Nacional de Estudos e Pesquisas Educacionais), presidido por Anísio Teixeira e pertencia ao Ministério da Educação e Cultura (MEC). Anísio convidou Darcy Ribeiro para assumir a direção científica do $\mathrm{CBPE}$, o qual constituiu imediatamente uma equipe interna interdisciplinar, além de uma rede de colaboradores externos para um triplo programa de estudos e pesquisas a contemplar: a) pesquisas de campo em municípios, zonas urbana e rural, representativos da diversidade brasileira; b) pesquisa bibliográfica e interdisciplinar de sistematização dos estudos e teses acerca da formação brasileira; c) pesquisas sociológicas sobre os processos de industrialização e urbanização (RIBEIRO, 1990).
} 
formação intelectual, sobretudo, num país de "terceiro mundo". A universidade serviu como laboratório dos rumos possíveis do Ensino Superior e da pesquisa na conexão com a Educação Básica, inspirando uma reforma universitária que, paradoxalmente, veio a se dar em condições inóspitas. A memória do projeto original da Universidade de Brasília revela, mais que seu fracasso, sua incompletude e a persistência de uma promessa. Nas continuidades e descontinuidades da história, é provável que a reflexão sobre esta tenha algo a nos ensinar em face das demandas do presente.

\section{A "Universidade Necessária", intelligentsia e missão}

Karl Mannheim $(1974 ; 1986)$ referia-se à possibilidade de se congregar, no âmbito das sociedades modernas, indivíduos cuja visão de mundo teria sido constituída mediante uma rigorosa formação letrada e comprometida com o "fazer histórico". Tal visão trazia a possibilidade de reconhecer e sintetizar elementos díspares do real e antecipar, em alguma medida, um projeto de sociedade superior à atual. Algo como uma antevisão propiciada pela "mentalidade utópica", definida como ideias que se opõem 'ao que existe', transcendendo a realidade fragmentada e reformulada como síntese, não para se realizar plenamente no mundo, mas para atuar como parâmetro de intervenção na realidade em contraste 'ao que há' a fim de garantir 'o que precisa haver'. Não seria utopia, é certo, se não se revelasse crítica e contrafática, um "estado de espírito incongruente com a realidade concreta" (MIGLIEVICH-RIBEIRO; MATIAS, 2006, p. 204), condição sine qua das mudanças avaliadas como desejáveis. Por isso, no confronto entre o projeto e o "campo de possibilidades" é que a história acontece.

A tese mannheimiana é controversa. O grupo portador da síntese teria, ele próprio, superado a cisão das classes e ideologias, algo inimaginável aos marxistas enquanto vivermos numa sociedade de classes. Curiosamente, porém, no Brasil, foram os intelectuais "de esquerda" os mais interessados leitores de Mannheim, de um lado, por sua aposta na ação racional e planejada visando à mudança social, e pelo elogio aos intelectuais públicos; de outro lado, no crucial momento em que ganhava substância um projeto de nação, a ideia de síntese propugnada pelo sociólogo húngaro não poderia ser desperdiçada.

É válido perceber Darcy Ribeiro como portador de utopias. Numa dimensão, uma utopia educacional, noutra, uma utopia nacional, noutra, ainda, uma utopia latino-americana, tendo reunido em seu pensamento variantes políticas, filosóficas, educacionais e estéticas (SOUZA RICARDO, 2007). Pensar Darcy Ribeiro, portanto, na chave da intelligentsia tende a somar para a compreensão de seus feitos e dos de sua geração: 
Darcy fez parte de uma geração de intelectuais e artistas que acreditava firmemente ser possível construir um projeto cultural abrangente para o Brasil e para a América Latina. Um projeto destinado a revolucionar as estruturas do país e do continente, e não apenas reformá-las [...] era uma geração de humanistas que queria nada menos que o todo. [...] E mais que isso: era uma gente que bebeu no modernismo antropofágico da Semana de 1922, ávida por conhecer e fazer valorizar as raízes mais profundas da nossa formação híbrida [...]. Darcy pertencia a esse tempo (FERRAZ, 2008, p. 10-11).

A UnB, deste ponto de vista, expressava a mentalidade utópica de uma geração intelectual acerca de um projeto acadêmico, educacional, arquitetônico e social, por isso chamado de "A Universidade Necessária", que se tornou, também, título de um de dois livros de Darcy escrito no exílio e publicado pela primeira vez em 1967, pela Editora Galerna, de Buenos Aires. Nele, Darcy Ribeiro fazia um balanço dos dilemas e desafios cruciais com os quais a universidade na América Latina se defrontava. Inspirava-o sua tese, desde "O Processo Civilizatório" (RIBEIRO, 1975a), acerca da "modernização reflexa" ou "atualização histórica" que se interpunha à "aceleração evolutiva". Os dois primeiros termos designavam o modo como os povos dominados eram compulsoriamente atrelados aos sistemas tecnologicamente mais avançados, com a perda de sua autonomia e, sabidamente, a destruição de suas matrizes étnicas. Enquanto que, por "aceleração evolutiva", compreendia-se os processos de desenvolvimento das sociedades que renovavam autonomamente seu sistema produtivo e instituições sociais, transitando de uma formação sociocultural para outra, como "povos que existem para si mesmos" (MIGLIEVICH-RIBEIRO \& MATIAS, 2006, p. 200). Entretanto, incapaz do domínio da ciência e das tecnologias, o Brasil, em pleno século XX, mantinha-se nos níveis mais baixos da divisão internacional do trabalho no capitalismo, condenado à "modernização reflexa".

A busca dos brasileiros pelo destino que lhes pertence por direito relaciona-se profundamente aos desafios da nação para a superação de seu atraso e de seu subdesenvolvimento que submete não somente o Brasil, se não a América Latina, à inserção subordinada no sistema mundial. Darcy Ribeiro havia escrito, na consecução de "O Processo Civilizatório" (1968), "As Américas e a Civilização" (2007), ambos publicados em 1968, no qual destacava o problema do colonialismo e dos neocolonialismos como centrais na explicação do presente:

Transmudaram-se, assim, de uma multiplicidade de povos autônomos, com suas tradições autênticas, em poucas sociedades espúrias de culturas alienadas, só explicáveis em seu modo de ser 
peça ação dominadora que sobre elas exercia uma força e vontade externa (RIBEIRO, 2007, p. 71).

Nosso "antropólogo das civilizações", contudo, não paralisava na constatação da violência dizimadora perpetrada pelo sistema colonial, porém, avançava na análise ao indicar que, incidentalmente, deu-se, também, o inesperado: "através de um esforço secular, realizado em surdina, nas esferas mais profundas e menos explícitas da vida dessas sociedades colonizadas, é que se foi operando o processo de reconstituição de si próprias como povos" (RIBEIRO, 2007, p. 72). A criatividade cultural fez, portanto, nascer, na chamada América Latina, etnias diferenciadas das matrizes originais a se transfigurar em nacionalidades, como se, dialeticamente, da negação do direito à existência brotasse uma inédita autenticidade, as gentes morenas/mestiças que desafiariam o ciclo civilizador europeu:

Os latino-americanos são hoje o rebento de 2 mil anos de latinidade, caldeada com populações mongoloides e negróides, temperada com a herança de múltiplos patrimônios culturais e cristalizada sob a compulsão do escravismo e da expansão salvacionista ibérica. [...] O novo se exprime na energia afirmadora que emerge das classes oprimidas, afinal, despertas para o caráter profano e erradicável da miséria em que sempre viveram; na assunção cada vez mais lúcida e orgulhosa da própria imagem étnico-mestiça; no equacionamento das causas do atraso e da penúria e na rebelião contra a ordem vigente (RIBEIRO, 2007, p. 77).

Para Darcy, como "povos novos" espraiados em todo o continente, populações plasmadas na amálgama biológica e na aculturação de etnias díspares no interior do enquadramento escravocrata, nasciam os brasileiros, os venezuelanos, os colombianos, os antilhanos, uma parte da população da América Central e do sul dos Estados Unidos. Os distintos povos europeus a colonizar as Américas geraram, linguisticamente, perfis culturais diferenciados: os luso-americanos, os hispano-americanos, os franco-americanos, os anglo-americanos e os batavo-americanos. Moldados pelo sistema de plantation, combinação do colonialismo e do capitalismo, chegavam ao século XX sem superar a "modernização reflexa" ou "atualização histórica" em prol da "aceleração evolutiva", o único real desenvolvimento porque autônomo. Naqueles inícios de 1960, Darcy Ribeiro estava plenamente consciente do papel nodal da universidade pública na realização da utopia do desenvolvimento nacional.

Sabia, certamente, que as universidades existiam dentro de sistemas sociais globais, sendo a elas mais fácil reproduzir ou refletir as características de uma 
sociedade apenas superficialmente moderna ("modernização reflexa") do que lhe imprimir alterações que conduzissem a um autêntico desenvolvimento ("aceleração evolutiva"). É por isso que, ao diagnosticar o presente das universidades latinoamericanas, Darcy Ribeiro avaliou que seu ritmo e tipo de crescimento não lhes davam possibilidades de, em um futuro próximo, desempenharem as funções mínimas de órgãos autônomos. Porém, se alterado o modelo de universidade, estaria ela apta a antecipar as transformações do contexto social, podendo nele intervir e provocar inovações intencionais. Neste caso, a instituição universitária poderia agir como agente de transformação e não mais como "freio de atraso". Caberia, para isto, explorar as contradições no desenvolvimento das estruturas e atuar em prol de sua superação dialética numa síntese superior.

Um modelo estrutural novo somente se impõe como uma necessidade impostergável porque as universidades latino-americanas não são capazes de crescer e de se aperfeiçoar nas condições atuais, a partir da estrutura vigente, com os recursos disponíveis. E, principalmente, porque esta estrutura serve mais à perpetuação do status quo que à sua transformação. Impõe-se, além disso, porque os remendos que se estão fazendo nesta estrutura, concretizados através de programas induzidos do exterior, ameaçam robustecer ainda mais o seu caráter retrógrado, aliviando algumas tensões e atendendo a algumas carências, precisamente para manter suas características essenciais de universidades elitistas e apendiculares (RIBEIRO, 1975b, p. 173).

Não se tratava, em suas palavras, de "reinventar a universidade se não lhe dar autenticidade e funcionalidade" (RIBEIRO, 1975b, p. 169), denunciando os interesses particularistas/patrimonialistas que se ocultavam nas universidades tradicionais e dando andamento às ações e às reações que modelariam a nova universidade, adequada às necessidades do desenvolvimento autônomo, sem o qual todos os países estão condenados indefinidamente ao atraso e à subserviência no plano mundial.

\section{A UnB como projeto: Anísio Teixeira e Darcy Ribeiro}

O final da década de 1950, conforme já mencionado, esteve marcado pela intensidade do debate acerca do papel da educação na definição dos rumos nacionais. Mantinham-se, na pauta do Congresso, as acirradas polarizações que uniram, de um lado, Anísio Teixeira e Darcy Ribeiro na luta pela ampliação da rede pública de ensino, nascido com o movimento da "Escola Nova" nos anos 1920, e, de outro, os defensores do ensino privado, representados, exemplarmente, por Carlos Lacerda e Dom Hélder Câmara. É nesse contexto que o tema da transferência da capital da república do Rio de Janeiro para o planalto central 
entra em cena. Nasceria Brasília, e Juscelino Kubitschek entregou nas mãos de Anísio Teixeira o planejamento da educação no novo distrito federal ${ }^{4}$, quando as ideias de Darcy Ribeiro também passaram a ressoar no poder central.

O urbanista da nova capital, Lucio Costa, havia introduzido em seu projeto uma ampla área destinada à cidade universitária com o respectivo Hospital das Clínicas e a previsão de instalação do Observatório. Eram 257 hectares na Asa Norte da cidade, junto ao Lago. Está dito por ele, em seu plano piloto, que seria um erro se a nova capital fosse concebida apenas como urbs e não como civitas, a saber, centro de nucleação e irradiação de cultura. Um dos opositores de sua pretensão era Israel Pinheiro, presidente da Companhia Urbanizadora da Nova Capital (Novacap) e administrador de obras que se mostrava mortificado por se querer "fazer uma universidade num deserto" (SALMERON, 2012, p. 39-41). Pinheiro temia, ainda, a presença de estudantes nas proximidades do governo e do Congresso e propunha conceder um terreno fora da capital para uma eventual construção futura. Sua resistência, porém, foi vencida e a UnB manteve-se no plano urbanístico de Lucio Costa.

Outro fato viria a pôr em xeque a criação da UnB e não tardaria muito. Dom Hélder Câmara procurou Juscelino Kubitschek para comunicar o propósito da Companhia de Jesus de erguer em Brasília a sua universidade, sem ônus para o governo. O Presidente pareceu não desejar se opor à ideia, ainda que isto significasse o fim do projeto da UnB. Inicia-se, assim, a série de obstáculos que Darcy Ribeiro teve que estrategicamente enfrentar para reverter as não poucas ameaças ao projeto da UnB.

Sem contar com o apoio de JK, Darcy decidiu equacionar a questão no âmbito em que nascera, ou seja, internamente, na Igreja Católica. Apelou para a ordem dominicana, que tradicionalmente opunha-se aos projetos jesuíticos. Expôs ao Geral da Ordem, Frei Matheus Rocha, seus motivos: o Brasil já possuía oito universidades católicas, quatro delas pontifícias, que formavam inúmeros profissionais, menos teólogos. $\mathrm{Na} \mathrm{UnB}$, sua oferta era a de que os dominicanos criassem o Instituto de Teologia Católica. A proposta foi levada ao Papa João XXIII por Frei Matheus e aceita. Como num milagre, não mais se falou numa universidade jesuítica em Brasília, abrindo-se novamente o "campo de possibilidades" para a UnB existir.

\footnotetext{
4 Vale enfatizar a continuidade entre escola e universidade contida no modelo educacional projetado por Anísio Teixeira bem como a constituição de um novo pensamento pedagógico inspirado nas ideias de John Dewey, a formar "cérebros" criativos e autônomos, sem distinção entre filhos de trabalhadores e filhos das elites. O sistema de ensino proposto era composto pelas seguintes instituições escolares: a) Centros de Educação Elementar, integrados por Jardins de Infância, Escolas-Classe e Escolas-Parque; b) Centros de Educação Média, destinados à Escola Secundária Compreensiva e ao Parque de Educação Média; c) Universidade de Brasília, composta de Institutos, Faculdades e demais dependências destinadas à administração, biblioteca, campos de recreação e desportos. (TEIXEIRA, 1961).
} 
Depois disso, Juscelino Kubitschek ainda surpreenderia Darcy Ribeiro com novos entraves. Encarregou o Ministério da Educação e nomes representativos das universidades públicas tradicionais, da gestão do projeto da UnB, tudo que Darcy Ribeiro mais temia. Para embargar esta decisão, foi de peso inestimável o apoio da Sociedade Brasileira para o Progresso da Ciência (SBPC). As aproximações entre Darcy Ribeiro e a SBPC haviam sido iniciadas na Reunião Anual de 1956, no Rio de Janeiro, ano em que a Sociedade se abriu às ciências humanas e Darcy fora incumbido de promover a interlocução destas com as demais ciências. A partir daí, haviam se iniciado grupos de trabalho sobre o planejamento da UnB, ocorrendo diversas reuniões informais na residência dos cientistas engajados ao longo daqueles quatro anos que anteciparam a realização, em 1960, em novo congresso da sociedade científica, de uma sessão especial dedicada à futura universidade.

Professor Roberto Salmeron, físico brasileiro na Organização Europeia para a Pesquisa Nuclear (CERN), um dos mais reconhecidos cientistas envolvidos na criação da UnB, relatou em seu livro "A universidade interrompida: Brasília 1964-1965” (2012) que não seria possível fazer justiça a todos os nomes que apostaram na nova universidade, ainda assim, devotou-se a recordar alguns deles. Rememorou, na educação em geral, Anísio Teixeira e Almir de Castro; nas Letras, Cyro dos Anjos; nas Artes e Arquitetura, Alcides da Rocha Miranda; nas Ciências Humanas, Victor Nunes Leal e Maria Yedda Leite Linhares; nas Biociências, Tito Cavalcanti, Antonio Rodrigues Cordeiro, Antonio Copuceiro, J. Moura Gonçalves, Warwick Kerr, Newton Freire Maia, Haity Moussatché, Walter Oswaldo Cruz e Maurício Rocha e Silva; na Matemática, Cândido Lima da Silva Dias, A. Ferreira Gomes, Maria Laura Mousinho Leite Lopes, Leopoldo Nachbin, Maurício Matos Peixoto; na Química, Jacques Danon, Ricardo Ferreira, Otto Richard Gottlieb, Júlio Puddles, Ary Coelho da Silva e Osé Israel Vargas; na Física, Guido Beck, Gabriel de Almeida Fialho, Jayme Tiomno, José Leite Lopes, e ele próprio, Roberto Salmeron (SALMERON, 2012, p. 75).

A participação direta da SBPC somada às adesões estratégicas de Cyro dos Anjos e de Victor Nunes Leal, respectivamente, subchefe e chefe da Casa Civil de JK, junto com o apoio evidente de Lúcio Costa e Oscar Niemeyer, encarregando-se pessoalmente do projeto físico da universidade, levaram por fim, o presidente da república a nomear Darcy Ribeiro, Cyro dos Anjos e Oscar Niemeyer responsáveis pela criação da UnB, descartando a hipótese de entregar para os reitores das universidades tradicionais o projeto da Universidade de Brasília.

Em 21 de abril de 1960, data da fundação da nova capital, Juscelino Kubitschek, impulsionado por Cyro dos Anjos, enviou para o Congresso Nacional a mensagem 
propondo a criação da Universidade de Brasília. Darcy Ribeiro passou a acompanhar, cotidianamente, o longo e exaustivo trabalho nas Comissões da Câmara dos Deputados e, depois, no Senado, administrando conflitos de interesses, buscando novos apoios, enfraquecendo a oposição, até ver o projeto de lei - que contou com a colaboração em sua redação de San Tiago Dantas - ser aprovado numa situação absolutamente excepcional da qual Darcy soube se beneficiar em prol do nascimento da UnB (TRINDADE, 2005).

Em verdade, um tumulto se instalara no Congresso Nacional quando da renúncia do presidente Jânio Quadros e o futuro era incerto. Darcy Ribeiro estava em Brasília num dos dias mais delicados da crise política e, em meio ao transtorno geral, conseguiu inserir na pauta do dia, por intermédio do presidente da sessão deputado Sérgio Magalhães - o projeto de lei relativo à criação da UnB, que foi aprovado junto com outros tantos pontos, para, em seguida, o feito ser repetido no Senado Federal, em que pese a oposição. Darcy recordava-se de seu sentimento então: "eu tinha em mãos, pois, toda uma lei admirável que deveria pôr em execução" (RIBEIRO, 1995, p. 10).

João Goulart, então na condição de primeiro-ministro, no curto parlamentarismo brasileiro, sancionou a Lei no 3.998 (BRASIL, 1961), criando, enfim, a Fundação Universidade de Brasília, em 15 de dezembro de 1961, e os cargos de reitor e vice-reitor foram entregues respectivamente a Darcy Ribeiro e a Anísio Teixeira. O Brasil vivia tempos de democracia instável e, para Anísio e Darcy, se a universidade iniciasse as aulas, nada mais poderia estancá-la. De fato, quatro meses depois, a UnB começou a funcionar. Dias ${ }^{5}$ descreve a mentalidade utópica que nela ganhava expressão:

Inaugurada em 21 de abril de 1962, sob inspiração de um grupo liderado por Darcy Ribeiro, Anísio Teixeira, Frei Matheus Rocha e contando com a colaboração de Oscar Niemeyer e Lucio Costa, a Universidade de Brasília representou, no contexto brasileiro, uma revolução na vida acadêmica. Em torno dos que conceberam a Universidade, reuniram-se professores comprometidos com as reformas de que o país necessitava para se modernizar, para se democratizar e para construir uma sociedade melhor, mais justa e mais igualitária. Era o protótipo da universidade cidadã (DIAS, 2013, p. 15).

\footnotetext{
Agradeço a gentil troca de e-mails com o professor titular aposentado da UnB, chefe do Departamento de Comunicação decano de extensão e vice-reitor Marco Antonio Rodrigues Dias que me indicou nova e fundamental bibliografia para esta pesquisa.
} 
Darcy Ribeiro traça uma linhagem que teria permitido a UnB ser concebida. Remonta a experiências dentro e fora da universidade que alertavam para a "tacanhez" da educação superior no Brasil (RIBEIRO, 1978, p. 48). Elogia a Escola Livre de Sociologia e Política (ELSP) em São Paulo, na qual ele mesmo se graduou. Tratava-se da primeira instituição de Ensino Superior organizada para promover a pesquisa e o ensino no campo das ciências humanas e sociais, criada logo após a derrota da revolução constitucionalista de 1932, por uma certa elite paulistana que, contudo, não conseguiu enxergar, segundo nosso autor, plenamente o potencial de sua iniciativa mesma, acabando por freá-lo. Destaca a criação da Universidade de São Paulo (USP) em 1934, e de sua Faculdade de Filosofia, Ciências e Letras (FFCL) que aspirou, mas não concretizou, à integração dos campos de saber. Chama atenção para a curta vida da Universidade do Distrito Federal (UDF), na cidade do Rio de Janeiro, que foi fundada em 1935 sob a influência dos ideais dos "pioneiros da educação" e a liderança de Anísio Teixeira. A UDF representava o trabalho exitoso de homens públicos de prestígio popular, configurando-se com o advento do Estado Novo, em ameaça à nova ordem imposta.

Não tardaria, assim, seu fechamento decretado em 1939. Dali em diante, a Universidade do Brasil passou a dominar o cenário e a definir o ethos das demais universidades no país, sem qualquer ambição integrativa e marcada por uma atmosfera vetusta e solene em nada convergente ao mundo em transformação. Com o passar dos anos, Darcy denuncia a burocratização e a cartorização da educação superior brasileira que "conduziu a extremos de irresponsabilidade e de clientelismo" (RIBEIRO, 1978, p. 55), multiplicando-se, por isso, "às centenas as falsas escolas superiores, deteriorando até níveis risíveis um ensino já muito precário" (RIBEIRO, 1978, p. 56). Nesse sentido, os planejadores da UnB estavam desafiados a superar tal "estado de calamidade" para que a universidade brasileira pudesse servir a uma nação desejosa de sair de sua condição persistente de colonialidade e mimetismo cultural, que a impedia de participar proativamente dos padrões internacionais de cultivo e difusão do saber.

Havia pontos específicos a serem enfrentados pela "universidade necessária" no país, dentre eles, o elitismo na educação, observado no estreitamento progressivo da oferta de matrículas no sistema público e gratuito junto à expansão desmedida do ensino privado de nível precário. Também cabia repudiar a sujeição à hegemonia catedrática que entregava o controle de um campo de conhecimento a uma única pessoa, reforçando o caráter paternalista e patrimonialista da universidade. Reconhecia-se, ainda, a carência de quadros pós-graduados sensíveis à realidade brasileira projetando-se, por isso, a criação de cursos de pós-graduação. Eram, também, desejáveis conquistas que levassem a uma saudável vida universitária por meio do incentivo à participação responsável dos estudantes na cogestão do 
cotidiano acadêmico com vistas à sua democratização. Tratava-se, sobretudo, de estancar o esbanjamento dos recursos públicos e romper o "encapsulamento" típico da universidade ao se estimular a comunicação extracurricular livre e vivaz no campus e fora dele, com a cidade e com o país, por meio de programas efetivos de difusão cultural e extensão universitária.

Não se inovariam cursos, programas, currículos, contudo, se a universidade não congregasse intelectuais e cientistas "de ponta", junto aos melhores talentos em início de carreira em condições alvissareiras de trabalho, dispondo da liberdade acadêmica, aguçados em sua imaginação e originalidade para dar respostas competentes aos desafios de seu tempo. Concomitantemente, havia de existir uma comunidade disposta a pensar uma inédita estruturação da universidade em institutos centrais e faculdades integrados.

No planejamento da UnB, cada instituto central agrupava todas as atividades de ensino, pesquisa e outras em sua área de saber. O curso tronco de Administração, Direito e Economia fundou o Centro de Ciências Humanas. O Centro de Artes inicialmente ligou-se ao curso tronco de Arquitetura e Urbanismo, até existir a Faculdade de Arquitetura e Urbanismo e o Centro de Artes propriamente, devendo-se registrar que as Artes, além da pintura e escultura, inovaram com a introdução das artes gráficas, do desenho artístico industrial, da fotografia, do cinema e da música. Por sua vez, foram inaugurados o Centro de Biociências, o Centro de Química e o Centro de Física, os primeiros Institutos Centrais de Ciências e Tecnologia. Havia ainda o Curso de Jornalismo e o Centro de Extensão Cultural. Também, o Instituto de Teologia, já mencionado. Em fase inicial de planejamento, encontravam-se a Faculdade de Medicina e a Faculdade de Tecnologia (SALMERON, 2012, p. 75-6; 92).

O currículo foi adaptado ao sistema de créditos no qual a aprovação do estudante numa disciplina era reconhecida em toda a universidade. Assim, se um estudante quisesse seguir nova orientação profissional não precisaria cursar outra vez as disciplinas em que já havia obtido aprovação. A carreira docente também era radicalmente modificada. $O$ primeiro nível da docência, o professor auxiliar, era o único que poderia ser ainda mestre. Todos os demais níveis (professor assistente; professor associado; professor titular) requeria, no mínimo, a titulação de doutor. Pensar algo assim no início da década de 1960 expressava um poder de antevisão raro (SALMERON, 2012, p. 96).

Era pressuposto que cabia à universidade pública e democrática atender à ampla $\mathrm{e}$ plural demanda por Ensino Superior no Brasil. Por isso, chama atenção, no projeto 
da UnB, o cuidado de Darcy Ribeiro em reconhecer, contudo, que os estudantes possuem expectativas diferentes em face da universidade, as quais podem mudar ou se consolidar ao longo dos anos. Nesse sentido, Darcy construiu uma tipologia de estudantes universitários, escapando do "modelo único", quer de aluno, quer de ensino. Em "A Universidade Necessária" (RIBEIRO, 1975b), vemos propostas três tipificações: a) consumidor; b) profissionalista; c) acadêmico. Este último é por ele dividido em dois subtipos: 1) técnico-profissional; 2) universitário. Tais denominações, talvez, fossem apreciadas nos anos em foram formuladas; hoje, contudo, parecem pouco explicativas, mas é seu conteúdo que interessa examinar.

O primeiro tipo referia-se ao estudante que ainda não amadureceu sua escolha profissional embora busque na universidade uma ambiência cultural e social diferenciada daquela que teria se apartado dela. Para ele, a UnB dará naturalmente o que necessita. O segundo tipo precisava e desejava trabalhar, visando, pela obtenção do diploma, à habilitação formal para o exercício de seu ofício. Não pretendia ser acadêmico ou cientista, nem podia ser obrigado a isto, o que significaria expô-lo a uma série de exigências, para ele, excessivas enquanto a qualificação mais objetiva de que necessitava era deixada de lado. Para este aluno, a universidade devia garantir todos os serviços educativos a que fazia direito e, mediante a comprovação de seu aproveitamento, emitir seu diploma, em tempo mais ágil que não o desanimasse a tentar obtê-lo. A oferta do turno noturno era, pois, completamente imprescindível bem como ofertar a este aluno cursos nas férias, com disciplinas e carga horária distintas em acordo com o ritmo realista de sua dedicação à universidade. Não serão alunos malformados - até mesmo porque todos os tipos de estudantes passavam pelo ciclo básico comum antes da opção pela carreira e pelo tipo de formação universitária que almejavam - porém, não se tornariam o estudante tipicamente acadêmico, sobre o qual recaía o maior investimento da universidade. Do perfil acadêmico, era requerida a dedicação exclusiva, o acompanhamento de professores em cujos programas de pesquisa se inseriam obrigatoriamente de modo a que seu aprendizado extrapolasse a sala de aula. O dia inteiro na universidade supunha, certamente, uma assistência diferenciada (bolsas de estudo desde o primeiro período), já tendo sido a toda comunidade acadêmica assegurados restaurante, residência e biblioteca equipada. Sabe-se que nasceriam deste grupo os futuros quadros qualificados no Brasil, lideranças empresariais, científicas, humanistas, que tenderiam a se destacar em seu campo de conhecimento, seja no mercado mais amplo (o técnico-profissional), seja na carreira acadêmica (o universitário).

No projeto da UnB, era enaltecido seu compromisso com a solução dos problemas nacionais e à missão de capacitar em nível de "primeiro mundo" os estudantes, somando-se a isto o empenho em sua formação cidadã. A exemplo, a Faculdade de 
Ciências Médicas havia sido estruturada, nas palavras de seu diretor, Dr. Antonio Marcio Lisboa, com proposições revolucionárias para formar um profissional capaz de atender às necessidades básicas de saúde da população - promoção, prevenção, recuperação, reabilitação - em diferentes níveis de atenção - primária (domiciliar, postos e centros de saúde), secundária (hospitais comunitários), e terciária (hospitais especializados e maternidades). Visava-se à formação integral, na unidade entre teoria e prática, em antagonismo à fragmentação do ensino provocada pela existência de inúmeras disciplinas apresentadas como isoladas e autossuficientes. A visão holística do ser humano e do paciente implicava o compromisso do médico também com as famílias e a comunidade. $\mathrm{O}$ aprendizado da medicina era realizado sob a forma de treinamento em serviço, no atendimento das demandas reais, isto é, o aluno aprendia fazendo (DIAS, 2013, p. 178).

O sistema de cátedra, visto como inibidor das ousadias intelectuais e contrário aos padrões internacionais do cultivo e da difusão do saber dada sua própria estrutura ensimesmada, não se compatibilizava com o projeto da UnB, tendo sido de início substituído pelos colegiados departamentais. A autonomia universitária era palavra de ordem no projeto que se desenhava com seu autogoverno democrático, exercido pelos corpos acadêmicos, cuja política de ensino, pesquisa e extensão não poderia sofrer ingerências do Estado ou de organismos internacionais. Autonomia esta que supunha responsabilidade pública:

O papel da universidade, para Darcy, indissocia-se da criação de uma consciência crítica. A universidade é uma instituição social fundamental, prenhe de ideologias e interesses, portanto, politizada, com a missão de nortear o desenvolvimento autônomo de sua nação. O postulado do saber científico neutro é recusado por Darcy que, não ingenuamente, sabe que a despolitização da universidade é nitidamente sua submissão aos interesses e à lógica dominante de distribuição de poder numa sociedade que não rompe com sua condição de atraso e de subdesenvolvimento. A transformação da sociedade exige a política - em seu sentido digno. A universidade tem, pois, um papel político: poder fazer (MIGLIEVICH-RIBEIRO; MATIAS, 2006, p. 202).

Enfatizava-se, ainda, o papel da universidade pública na integração da vida social, política e cultural brasileira voltada à construção de um diálogo internacional permanente, especialmente com as demais nações latino-americanas (ALENCAR, 1969, p. 219-220). Darcy Ribeiro era conhecedor de que, em contraste com a América Hispânica, o Brasil chegara à independência sem contar com uma única universidade. Em que pese esse registro, era para ele nítido, que a não superação 
da já citada "modernização reflexa" no continente deixava todas as universidades até então atadas à "recolonização cultural", a reboque de decisões que lhes eram exógenas, contra o que a "universidade necessária" se insurgia.

\begin{abstract}
A América Latina, imersa num regime neocolonial de atualização histórica, ficou para trás até cair nas atuais condições de dependência em relação aos Estados Unidos. Mesmo contando com uma tradição universitária própria e secular, deixou-se recolonizar culturalmente pelo modelo francês de universidade e, mesmo este, só logrou implantar mediocremente (RIBEIRO, 1982, p. 90).
\end{abstract}

Projetos de reforma universitária são conhecidos, a exemplo de Córdoba, na Argentina. A UnB representava um passo além. Não se previu, contudo, que, com dois anos de vida, a recém-nascida universidade, ainda frágil, sofreria o Golpe de $1^{\circ}$ de abril de 1964 com o flagrante estreitamento, se não sufocamento, de seu "campo de possibilidades".

\title{
4 O Golpe e o sufocamento do "campo de possibilidades"
}

João Goulart que se tornou, após a renúncia de Jânio Quadros, primeiro-ministro no curto e tenso parlamentarismo brasileiro, e depois, presidente da república com o retorno do regime presidencialista, reunira desafetos que vinham desde os tempos de sua atuação como ministro do trabalho de Getúlio Vargas. O clima de polarização comunismo versus capitalismo não ajudava e fazia com que as reformas de base do Governo Jango, em que pesem serem realizadas em consonância à ordem democrática, fossem interpretadas e divulgadas indevida $\mathrm{e}$ massivamente como uma aproximação ao bloco socialista. Acusava-se Jango até de querer "rasgar a constituição", e, paradoxalmente, para evitar isto, os militares e os civis golpistas o fizeram acintosamente.

Os principais elementos deflagradores do golpe tinham natureza política: o medo, a insegurança e a reação ao processo de esquerdização ou de "comunização" supostamente em curso no país. As representações anticomunistas, que foram dominantes nos discursos favoráveis ao golpe, expressavam o temor em relação aos movimentos sociais no campo [...] à força crescente dos sindicatos [...] à politização dos subalternos das Forças Armadas e à esquerdização dos jovens universitários. Além de expressarem o medo difuso despertado pelo aumento da influência da esquerda, tais representações tinham a vantagem de colocar o problema em linguagem compreensível para a sociedade, há muito acostumada a ouvir discursos sobre o "perigo 
vermelho". Por outro lado, tal linguagem permitia conferir mais gravidade ao quadro político, inscrevendo a situação brasileira nos parâmetros da Guerra Fria (MOTTA, 2014, p. 23).

João Goulart caiu sem oferecer resistências. Há relatos de que, apesar da contrariedade de seus apoiadores, a exemplo de Leonel Brizola, então governador do Rio Grande do Sul - inconformado que um governo legítimo e legal fosse simplesmente destituído - o presidente deposto não quis correr o risco de instaurar uma guerra civil no Brasil, informado da presença de forças bélicas norte-americanas próximas à baía de Vitória e do Rio de Janeiro que tornariam qualquer reação inócua. $\mathrm{O}$ ônus dessa decisão foi também alto, mas é fato que ninguém supunha, à época, que seriam 30 anos de ditadura no Brasil, nem as próprias lideranças golpistas (RIBEIRO, 2010a,b).

Imediatamente, a UnB sofreu as consequências do assalto ao poder. O campus foi transformado em cenário de guerra, com a ocupação por tropas da Polícia Militar mineira e do Exército de "armas em punho" (MOTTA, 2014, p. 31). A propaganda de ódio a UnB já se alastrara. Não se tratava de conhecer seu projeto acadêmico, mas de aniquilá-lo haja vista que, numa estreita avaliação, o campus seria um "antro comunista" alimentado, dentre outros, pelos "marxistas" Darcy Ribeiro, Oscar Niemeyer, Claudio Santoro, Fritz Teixeira de Salles.

[...] quando a UnB, assim como todo o país, foi sacudida pelo movimento militar de 1 de abril de 1964. A 9 de abril, tropas da Polícia Militar de Minas Gerais e efetivos do Exército, sediados em Mato Grosso, ocupando 14 ônibus e trazendo três ambulâncias de serviço médico - não se sabe até hoje o porquê, mas era esperada uma reação armada por parte da Universidade! - em uniforme de campanha e portanto equipamento de combate, invadiram o campus universitário. À invasão seguiu-se uma minuciosa batida $\mathrm{e}$ revistamento das secretarias da reitoria dos demais departamentos, em particular da Biblioteca Central, cujo prédio, inclusive os gabinetes dos professores do Instituto Central de Ciências Humanas, sediado no primeiro andar, foi interditado por dezesseis dias. Com as tropas, vinha uma lista de professores a serem aprisionados. Doze desses professores, puderam ser encontrados, seja no campus, seja em suas residências, onde foram chamados pela reitoria e pelos colegas que julgaram melhor que seria os mesmos se apresentarem, já que nada tinham a ocultar e, assim, poderiam facilmente desfazer equívocos. Nossa surpresa foi, porém, que muitos deles ficaram 
presos no quartel do batalhão da Guarda Presidencial de treze a dezoito dias (MACHADO NETO, 1969, p. 251).

O reitor Anísio Teixeira foi demitido e destituído o Conselho Diretor da Fundação Universidade de Brasília. Zeferino Vaz, da Faculdade de Medicina de Ribeirão Preto - autoridade sanitária que já entrara em choque com o movimento sindical da área da saúde e era assumidamente antijanguista - foi nomeado como interventor, tomando posse imediatamente para ser, em seguida, "eleito" membro do Conselho Diretor da Fundação Universidade de Brasília (FUB).

Num primeiro momento, o reitor pro tempore tentou abrir o diálogo com a comunidade acadêmica, anunciando que os professores e alunos presos seriam libertados e que se comprometia em continuar a obra de Darcy Ribeiro, o que repercutiu bem internamente. Os ânimos dos que abraçaram o projeto da Universidade de Brasília fortemente abalados não se encontravam ainda derrotados e "prevaleceu a tese de que, considerada a situação anormal em que vivia o país, valia a pena perseverar perseguindo o ideal de manter a UnB malgrado a afronta" (MACHADO NETO, 1969, p. 252). Os professores que não estavam presos, aos poucos, retomaram as aulas e as pesquisas no estado de exceção enquanto lhes foi possível respirar.

\begin{abstract}
Apesar dessa interferência vital, as atividades continuaram com o mesmo vigor e a universidade tomou impulso raramente visto em tão pouco tempo em universidades de nosso país. Todos os setores desenvolviam-se rapidamente, chamando atenção de colegas de outros centros, que nos contavam. Alguns cientistas e artistas do exterior estavam colaborando conosco e outros queriam vir colaborar, e instituições estrangeiras auxiliavam-nos substancialmente devido ao prestígio dos responsáveis por projetos (SALMERON, 2012, p. 29).
\end{abstract}

Os ataques externos, contudo, não cessaram. Foi instaurado um inquérito policial militar (IPM) para a apurar a subversão no campus e, com ele, o clima de "terrorismo cultural" tomou conta da UnB. Zeferino Vaz, cedendo às pressões, expulsou 16 docentes e um discente sem acusação, sem processo jurídico, sem direito de defesa (APARECIDA, 1995, p. 45). O argumento formal se restringia a: "eram indisciplinados e a indisciplina deveria ser considerada uma subversão" (SALMERON, 2012, p. 30). Os alunos denunciavam os arbítrios por meio das mobilizações e exigiam a readmissão de seus professores, colocando-se, também, como alvo das perseguições políticas. 
As mentiras e difamações multiplicavam-se. Coordenadores de cursos e faculdades bem como as principais autoridades acadêmicas insistiam no diálogo com o reitor que, por sua vez, era duramente criticado por setores do governo por não conseguir controlar as contestações. Entre junho e setembro de 1965, a crise foi agudizada e vários alunos foram expulsos. Zeferino Vaz, após uma audiência com o presidente militar Castello Branco, anunciou sua renúncia. O novo reitor empossado, Laerte Ramos de Carvalho, professor da USP, suspendeu as atividades acadêmicas e solicitou ao DOPS o envio de tropas policiais ao campus. Mais 15 professores foram demitidos. A comunidade universitária reagiu, mas o diálogo havia sido suspenso pelo reitor, deflagrando, como consequência, a demissão voluntária de 223 professores na maior diáspora da história das universidades. Os estudantes, ainda que fatalmente prejudicados, deram irrestrito apoio a seus mestres.

Essa demissão coletiva, caso único na história da universidade no mundo, foi espontânea, não foi programada, nem dirigida do exterior como alguns ridiculamente pretenderam. Por causa da determinação e da união dos docentes, houve quem duvidasse de sua espontaneidade. Por que tal atitude de 223 pessoas? Que fatos levaram a tantos, conscientes e responsáveis, a se convencer de que não era mais possível continuar trabalhando nas condições que lhes eram impostas? A situação podia ser resumida numa frase, em termos simples: seria possível manter a dignidade de cidadãos e de professores construindo uma universidade cujo corpo docente deveria estar sujeito às arbitrariedades de um reitor e de um ministro da Educação que julgavam normal receber instruções do Serviço Secreto do Exército e de outros serviços policiais? O Ministro da Educação dizendo em entrevistas que educação é assunto de segurança nacional? (SALMERON, 2012, p. 31-32).

Darcy Ribeiro acompanhou a destruição do projeto da UnB no exílio onde se descobriu "cidadão latino-americano". Iniciava, assim, sua nova trajetória como "reformador de universidades" na América Latina (além de ter atuado na criação da Universidade de Argel). A biografia de Darcy Ribeiro confunde-se com seu pensamento e com sua missão em prol da "universidade necessária". Noutras trilhas, noutro "campo de possibilidades", seu pensamento-ação ousaria persistir.

\footnotetext{
Dentre outros, Darcy Ribeiro trabalhou na Universidade da República Oriental do Uruguai, onde escreveu "A Universidade Necessária". Propôs as reformas da Universidade Central da Venezuela e do sistema universitário peruano na América do Sul. Entre uma e outra, trabalhou no Governo Allende, no Chile. Colaborou na reestruturação da Universidade de Argel, elaborou o projeto básico de implantação da Universidade Nacional de Costa Rica e, ainda, ofereceu para a Universidade Autônoma do México o plano de sua Faculdade de Educação e Comunicação (RIBEIRO, 2010c).
} 


\section{Considerações Finais}

Uma universidade assim, livre e libertária, só pode sobreviver numa ordem democrática. Quando subvertida a institucionalidade constitucional, se tomou do povo a liberdade de buscar os caminhos de sua própria emancipação - precisamente porque

ele os estava encontrando - os custódios da regressão tiveram que reprimir todos os que se opunham à nova ordem e, entre eles, naturalmente, também a UnB (Darcy Ribeiro, UnB: invenção e descaminho, 1978, p. 84).

No ano de 1991, em sua primeira fala ao Senado, o senador Darcy Ribeiro, aplaudido de pé ao final por longos minutos, dentre outros, por Nelson Carneiro, Mario Covas, Fernando Henrique Cardoso (FERRAZ, 2008, p. 17), contou o sentimento de derrota dele e de Anísio Teixeira com a "interrupção" da UnB em 1965: "juntos, vimos todas essas conquistas serem desmerecidas e degradadas por uma ditadura que impôs ao Brasil retrocessos em todos os campos. Inclusive, sobre nosso sistema educacional já tão precário que foi levado à calamidade" (RIBEIRO, 2008, p. 78).

Geralda Dias Aparecida (1995), na UnB, professora de História, relatou que a diáspora dos professores durou de outubro de 1965 até início de 1966. A universidade, dada a intransigência do regime militar, havia perdido então $80 \%$ de seu corpo docente. Laerte Ramos foi substituído, em novembro de 1967, pelo novo reitor Benjamin Dias que conseguiu, paulatinamente, "repovoar" a UnB com novos quadros profissionais. Seu discurso era o da técnica e da eficiência, não tolerando qualquer movimento político reivindicatório.

Os acordos MEC-Usaid ameaçavam seriamente a universidade pública e autônoma na extensão do território nacional. Na contramão da "aceleração evolutiva" propugnada por Darcy Ribeiro. A sociedade civil resistia, sobretudo, o movimento estudantil que, em junho de 1967, havia realizado no Rio de Janeiro o "Seminário Nacional Imperialismo MEC-Usaid", promovido pela União Metropolitana dos Estudantes, cujo resultado era a recomendação de que todos os acordos fossem amplamente estudados dentro das unidades universitárias. Dali para a frente, os enfrentamentos entre os estudantes e o regime ditatorial foram aprofundados, assim como, as retaliações.

Em 28 de novembro de 1968, deu-se a "reforma universitária", com a promulgação da Lei $\mathrm{n}^{0} 5.540$ (BRASIL, 1968), que fixava as normas de organização e funcionamento do Ensino Superior e sua articulação com a escola média, e dava 
outras providências. Paradoxalmente, a UnB, despojada do conteúdo crítico, tornou-se a primeira universidade no Brasil não somente a se adequar ao ritmo da reforma universitária, como a lhe servir de referência.

É espantoso que 15 dias após a reforma, tenha se dado "o golpe dentro do golpe", como também ficou conhecido o Ato Institucional no 5 (AI-5) de 13 de dezembro de 1968, pelo general-presidente Costa e Silva, fechando as assembleias estaduais, aposentando compulsoriamente ministros do Supremo Tribunal Federal e, finalmente, suspendendo a garantia do habeas corpus para os presos políticos. No mesmo dia, o governo baixou o Ato Complementar $\mathrm{n}^{\circ} 38$, colocando o Congresso indefinidamente em recesso (FREIXO; FREITAS, 2008). Explicitava-se assim também que a citada reforma, inspirada nos princípios da recém-criada Universidade de Brasília, suas linhas estruturais e seus modos de ação, nascia condenada.

De fato, quando se promulgou a chamada "reforma universitária de 1968 " e, posteriormente, todos os remendos adispostos a ela, aquelas liberdades já vieram castradas, e aquelas renovações estruturais degradadas. O mais grave, porém, é que os velhos catedráticos e a reação acadêmica já se haviam reapossado da universidade. Em suas mãos, como era inevitável, cada inovação se converteu num escárnio, agravando muitas vezes os problemas que poderiam ter resolvido. Assim é que pululam pelo Brasil afora os simulacros dos institutos centrais; as departamentalizações de mentira; o regime de crédito funcionando pior que os antigos seriados; os currículos de curta duração deteriorando os títulos profissionais; os falsos programas de pós-graduação falsificando a moeda acadêmica, que são os graus de mestre e doutor (RIBEIRO, 1978, p. 64).

No fatídico 13 de dezembro de 1968, poucos sabiam, exceto os militares, que Darcy Ribeiro estava no Brasil, na primeira de suas tentativas de regresso. Havia chegado ao limite seu desespero por estar longe dos acontecimentos mais dramáticos dos quais era informado parcialmente no exílio. Sem prever o desfecho, no início daquele ano, chamou seu advogado Wilson Mirza e pediu "que avisasse à ditadura que iria desembarcar no avião tal, à hora tal, no aeroporto do Galeão. Não queria ser preso pelo oficial do dia e sim pela ditadura, se essa fosse a resolução" (RIBEIRO, 2010a p. 98). Enviado ao DOPS, respondeu um questionário e viveu três meses em liberdade. Foi preso no dia seguinte à edição do AI-5. Rodou alguns quartéis até permanecer detido na Ilha das Cobras, o quartel-general dos fuzileiros navais até setembro de 1969, quando após seu 
julgamento pelo tribunal de oficiais da Marinha, foi absolvido. No dia seguinte de sua soltura, soube que os militares ordenaram novamente sua prisão e, velozmente, com o apoio do sociólogo venezuelano José Augusto Silva Michelena, conseguiu um visto consular para entrar em Caracas - após ter sua entrada recusada pelo cônsul dos EUA em que pese convite acadêmico - onde se estabeleceu e passou a trabalhar como professor visitante na Universidad Central de la República (RIBEIRO, 1997).

Darcy Ribeiro nunca deixaria de falar sobre se fazer universidade pública como possibilidade de se refundar a nação. Constata-se sua aposta reiterada na educação como promotora de um ethos coletivo e solidário. Na perspectiva do intelectual mannheimiano, seus engajamentos jamais foram fonte de abnegação e ceticismo mas serviram ao adensamento de sua capacidade crítica. Nem o exílio o afastou de suas convicções mais genuínas. Soube reinventar-se e persistir, ainda que ciente do "campo de possibilidades" instalado:

Falar de universidade, para mim, é voltar a um tema tão familiar que, de tão familiar, torna-se cansativo. Tantas vezes pensei a universidade, tantas vezes repensei a universidade, tantas vezes projetei a universidade, tantas vezes propus a reforma da universidade. Dando um parecer sintético agora, eu diria: a universidade é o útero na qual a classe dirigente se reproduz, e se reproduz com enorme eficácia; $99 \%$ das pessoas que saem da universidade saem com a sua carreira, qualificados socialmente para não ser povo; é uma máquina de fazer com que as pessoas se convertam em "não-povo", e saem todos para serem perfeitos guardiões do sistema: para se casar, para se comportar bem (RIBEIRO, 1978, n.p),

Na história, a capacidade de projetos supraindividuais obterem êxito, se prolongarem e se desdobrarem dificilmente é sabido a priori. Somente as análises a posteriori de trajetórias reais podem nos permitir o exercício da crítica ao imaginar coerências e incoerências nos traçados humanos que, de algum modo, alimentam nossa identidade hoje, provendo a articulação de novos - ou nem tanto - projetos. A geração de Darcy Ribeiro, marcada pela utopia, concretizou uma missão. É crível pensar, contudo, que tal missão não se encerrava naquelas fortes personagens. Projetos e "campo de possibilidades" se renovam. 


\section{Darcy Ribeiro and the UNB: intellectuals, design and mission}

\section{Abstract}

The history of the University of Brasilia (UnB) -since its original conception, struggles for its implementation, until the military coup suffered in 1964 with its campus invaded by military troops- is remembered for being related to the debate by Brazilian public intellectuals that, in the 1950s and 1960s, defended a certain nation project that had seen in education and science its constituent forces. I use the Intelligentsia category of Mannheim that strengthened the argument of the intellectuals engaged in social planning with a view to necessary changes. Darcy Ribeiro is one of those intellectuals. Upon the notions of "project" and "mission" I try to explain what could also be called "generation of utopia", being UnB one of the ongoing projects that was born within a "range of possibilities" that was abruptly modified. Revisiting the mission contained in UnB, updating it because of unprecedented "fields of possibility", may be a necessary task for the educational debate today.

Keywords: Darcy Ribeiro. Intellectuals. University. UnB. Field of possibilities.

\section{Darcy Ribeiro y Unb: intelectuales, proyecto y misión}

\section{Resumen}

La historia de la Universidad de Brasilia (UnB), desde su concepción original, luchas por su implantación y el golpe sufrido en 1964, teniendo su campus invadido por las tropas militares, es recordada para sumar al debate sobre los intelectuales públicos brasileños que, en los años de 1950 y 1960, defendieron un proyecto de nación que tenía en la educación y en la ciencia sus fuerzas constituyentes. Uso la categoría Intelligentsia de Mannheim que refuerza el argumento del intelectual comprometido con el planeamiento social con miras a cambios necesarios. Darcy Ribeiro es uno de ellos. Por medio de las nociones de "proyecto" y "misión" trato de explicar aquella llamada "generación de la utopía", siendo la UnB uno de los proyectos en curso, que nació dentro de un "campo de posibilidades" abruptamente cambiado. Volver a la misión contenida en la UnB, actualizándola en razón de los nuevos "campos de posibilidades”, puede ser una tarea necesaria para el debate educativo actual.

Palabras clave: Darcy Ribeiro. Intelectuales. Universidad. UnB. Campo de possibilidades. 


\section{Referências}

ALENCAR, H. Apêndice I. A Universidade de Brasília. Projeto Nacional da Intelectualidade Brasileira. In: RIBEIRO, D. A universidade necessária. Rio de Janeiro: Paz e Terra, 1969. p. 213-38.

APARECIDA, G. D. UnB em dois tempos. Carta: falas, reflexões, memórias, n. 14 , p. 37-53, 1995.

BRASIL. Lei no 3.998, de 15 de dezembro de 1961. Autoriza o Poder Executivo a instituir a Fundação Universidade de Brasília,e dá outras providências. Diário Oficial da União, 15 dez. 1961.

. Lei $\mathrm{n}^{\mathrm{0}} 5.540$, de 28 de novembro de 1968. Fixa normas de organização e funcionamento do Ensino Superior e sua articulação com a escola média, e dá outras providências. Diário Oficial da União. 29 nov. 1968.

DIAS, M. A. R. UnB e comunicação nos anos 1970: acordo tácito, repressão e credibilidade acadêmica. Brasília, DF: Ed. UnB, 2013.

FERRAZ, I. G. Introdução. In: . Darcy Ribeiro: utopia Brasil. São Paulo: Hedra, 2008. p. 9-18.

FREIXO, A.; FREITAS, J. V. Introdução. In: MUNTEAL FILHO, O.; FREIXO, A.; FREITAS, J. V. (Orgs.). Tempo negro, temperatura sufocante: estado e sociedade no Brasil do AI-5. Rio de Janeiro: Contraponto, 2008. p. 9-35.

MACHADO NETO, A. L.. Apêndice 2: A ex-universidade de Brasília: significação e crise. In: RIBEIRO, D. A universidade necessária. Rio de Janeiro: Paz e Terra, 1969. p. 239-60.

MANNHEIM, K. Ideologia e utopia. Rio de Janeiro: Guanabara, 1986. . Sociologia da cultura. São Paulo: Perspectiva, 1974.

MIGLIEVICH-RIBEIRO, A. Heloísa Alberto Torres e Marina de Vasconcelos: pioneiras na formação das ciências sociais no Rio de Janeiro. Rio de Janeiro: Ed. UFRJ, 2015.

MIGLIEVICH-RIBEIRO, A.; MATIAS, G. R.. A universidade necessária em Darcy Ribeiro: notas sobre um pensamento utópico. Ciências Sociais. Unisinos, v. 42, n. 3, p. 199-205, set./dez. 2006. 
MOTTA, R. P. S. As universidades e o regime militar: cultura política brasileira e a modernização autoritária. Rio de Janeiro: Zahar, 2014.

PEIRANO, M. Uma antropologia no plural: três experiências contemporâneas. Brasília, DF: Editora UnB, 1992.

RIBEIRO, D. A universidade necessária. 2. ed. Rio de Janeiro: Paz e Terra, $1975 b$. . A universidade necessária. 4. ed. Rio de Janeiro: Paz e Terra, 1982. . As Américas e a civilização: processo de formação e causas do desenvolvimento desigual dos povos americanos. São Paulo: Cia das Letras, 2007. . Confissões. São Paulo: Companhia das Letras, 1997. . Golpe e exílio. Rio de Janeiro: Fundar, 2010a. . Jango e eu. Rio de Janeiro: Fundar, $2010 \mathrm{~b}$. . O Brasil como problema. Rio de Janeiro: Fundar; Brasília, DF: Edunb, 2010c.

. "Primeira fala ao Senado". In: FERRAZ, I. G. Darcy Ribeiro: utopia Brasil. São Paulo: Hedra, 2008. p. 75-96.

. O processo civilizatório: etapas da evolução sóciocultural. Rio de Janeiro: Civilização Brasileira, 1975a.

. Prólogo. Carta: falas, reflexões, memórias, n. 14, p. 7-11, 1995. . Testemunho. São Paulo: Siciliano, 1990.

. UnB: invenção e descaminho. Rio de Janeiro: Avenir, 1978.

. Voz viva da América Latina. Rio de Janeiro: Tiro de

Letra, 1978. Disponível em: <http://www.tirodeletra.com.br/ensaios/ VozvivadaAmericaLatina.htm>. Acesso em: 10 abr. 2015.

SALMERON, R. A. A universidade interrompida: Brasília 1964-1965. Brasília, DF: EdUnB, 2012.

SANTOS, W. G. Paradigma e história: a ordem social burguesa na imaginação social brasileira. In: São Paulo: Duas Cidades, 1978. (Org.). Ordem burguesa e liberalismo político. 
SOUZA RICARDO, P. A. G. Utopia Selvagem, de Darcy Ribeiro e a Idade da Terra, de Glauber Rocha: o visivel, as vozes e a antropofagia. 2007. $107 \mathrm{f}$ .[Disssertação de mestrado em Estudos Literários]. — Faculdade de Letras, Universidade Federal de Minas Gerais, Belo Horizonte, 2007.

TRINDADE, H. Apresentação. In: TEIXEIRA, A. Ensino superior no Brasil: análise e interpretação de sua evolução até 1969. Rio de Janeiro: EDUFRJ, 2005. p. 9-43.

VELHO, G. Individualismo e cultura: notas para uma antropologia da sociedade contemporânea. Rio de Janeiro: Zahar, 1981.

VILHENA, L. R. Projeto e missão: o movimento folclórico brasileiro 1947-1964. Rio de Janeiro: Funarte, 1997.

VILLAS BÔAS, G. Os portadores da síntese: sobre a recepção de Karl Mannheim. Cadernos CERU, v. 2, n. 13, p. 125-43, 2002.

TEIXEIRA, A. Plano de construções escolares de Brasília. Revista Brasileira de Estudos Pedagógicos, v. 35, n. 81, p. 195-199, jan/mar. 1961.

\section{Informações da autora}

Adelia Miglievich-Ribeiro: Doutora em Sociologia (PPGSA/IFCS/UFRJ). PDS Faperj/ ProPEd-Uerj; Professora Adjunta do Departamento de Ciências Sociais da Universidade Federal do Espírito Santo (Ufes) e docente permanente do PPG em Ciências Sociais e do PPG em Letras (mestrado e doutorado). É PQ-Produtividade CNPq, nível 2 bem como pesquisadora Fapes com o projeto "Intelectuais Andarilhos na América Latina: o Brasil no exílio (1960-70)". Líder do Núcleo de Estudos em Transculturação, Identidade e Reconhecimento (Netir), cadastrado no DGP-CNPq, e do Grupo de Estudos en Intelectuais, Conhecimento e Crítica (Geicc). Membro da Rede Brasileira de Pesquisadores Latinoamericanistas e Caribeanistas. 